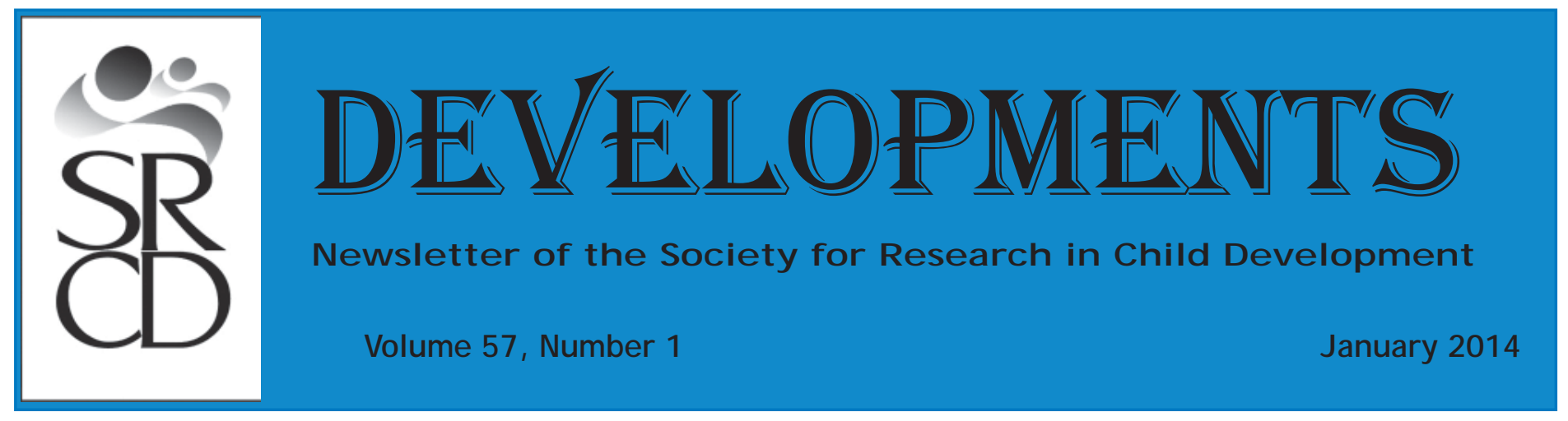

\title{
Notes from the Executive Director
}

\section{The Rockefeller Archive Center}

by Lonnie Sherrod, Executive Director

The SRCD's Governing Council is currently exploring what more we should be doing in documenting the history of child development research. As part of this effort, in early December I attended a workshop on the history of childhood and the field of child development research sponsored by, and held at, the Rockefeller Archive Center (RAC) near Tarrytown, NY. Involving a small group of historians and developmental scholars, the workshop was aimed at laying the foundation for the "next generation" of scholarship on the history of developmental research. I was not familiar with the Center and expect that the same may apply to many of our members. Hence, I describe the Center in this article because it offers numerous historical and contemporary research possibilities on children and youth and the philanthropy that has nourished the field, all of which should be of interest to developmental scientists.

The RAC is housed in the magnificent home of Martha Baird Rockefeller, second wife of J ohn D. Rockefeller, J r. Known as Hillcrest, it was completed in 1963. Its renovated 10-car garage now houses the RAC's research and education department. The archival storage vaults are not accessible to researchers but there are work spaces for scholars in the Center's reading room.

\section{IN THIS ISSUE}

Notes from the Executive Director....1-2

Report from the OPC. .3

Teachers' Corner.............................4-5

New Books by Members....................5

SECC Report................................6

Building Infrastructure Workshop..............7

Twenty Most Fascinating Studies in Child Psychology................................ 8-9

Fellowship Opportunity......................9

Victoria S. Levin Grant Winner..................10

Members in the Media.......................11

Submission Guidelines...................12
The RAC has numerous collections of relevance to the history of childhood and child development research. First, they have the Rockefeller Family Archives, in particular the Welfare Youth Series in Record Group Two. Also, the records of a number of institutions associated with the Rockefellers are housed there, including the Rockefeller University, the Rockefeller Foundation, and the Rockefeller Brothers Fund. J ohn D. Rockefeller, Sr. was active in and supportive of numerous child serving organizations in the early 1900s, including Baptist orphanages, Black schools and YMCAs. Early Rockefeller philanthropic organizations worked to improve the lives of children. Other Rockefeller initiatives include the General Education Board which supported African-American education in the South and worked on issues such as school lunches and physical education as well as the Bureau of Social Hygiene, which covered child and maternal health, family relations, and juvenile justice. J ohn D. Rockefeller, J r. created the Davison Fund (1930-1942), an organization interested in child welfare.

As some members may be aware, the Rockefellers were very involved in the origins and early history of the field, including the founding of SRCD. The Laura Speltman Rockefeller Memorial (LSRM), founded in 1918, was especially important to the early field of child development research and to the establishment of SRCD. The LSRM promoted the welfare of women and children through grants that supported organizations such as the Boy and Girl Scouts, YMCAs, the Child Study Association, and the Merrill-Palmer Institute. It also underwrote the first child development institutes at Columbia, Minnesota, Berkeley, and Toronto. Perhaps most important was funding for the National Research Council 


\section{Notes fRom the EXeCUtive DiRector}

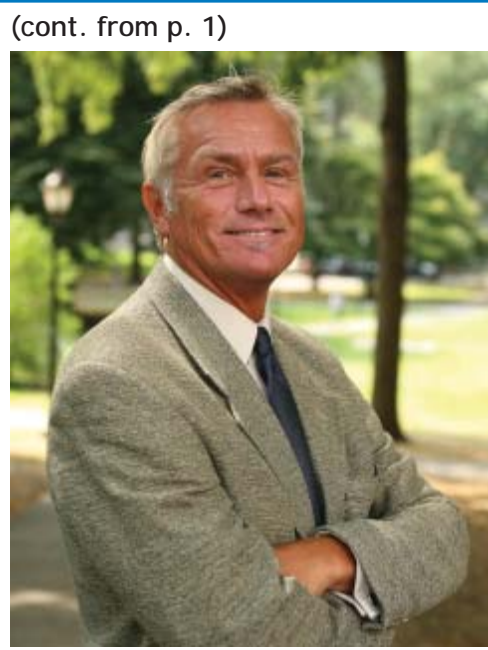

(NRC) Committee on Child Development (CCD) of the National Academy of Sciences. The CCD was formed to ensure that the field of child development would have a solid research base. The CCD launched SRCD in 1933 and SRCD's first meeting of 100 researchers was held in Chicago in J une 1933. In fact, SRCD did not become independent from the NRC until 1948.

Various Rockefeller grant-making institutions have retained their interest in social science research on child welfare, the humanities in arts and education for children, and child health. The third generation of Rockefeller philanthropy continues to fund child supporting organizations in New York and elsewhere.

It's worth noting that the RAC also has a number of significant archival collections relevant to children and child development research that were generated by institutions not affiliated with the Rockefeller family. These include the Commonwealth Fund, the Ford Foundation, the Foundation for Child Development, the Markle Foundation, the Russell Sage Foundation, the Social Science Research Council (SSRC), and the William T. Grant Foundation. As members know, the Foundation for Child Development and the William T. Grant Foundation have been supportive of research on child and youth development since the early 1900 s up to the present day. The SSRC has been important in launching and nourishing new interdisciplinary areas of research on child and youth development.

As for the SRCD's own older archives, they are now spread across three different sites but not at the RAC. The Governing Council is currently exploring possibilities for the archiving of all of our records. In the meanwhile, a wealth of supportive and background material on the SRCD is located in many of the collections housed at the RAC, and the RAC staff have produced a basic bibliography on child research that is several pages long. SRCD members such as Emily Cahan, Willard Hartup, Stephen Lassonde, Alice Smuts, and Richard Weinberg have previously used the archives to explore a variety of topics including gender roles in early child psychology, the Minnesota Institute of Child Development, schooling and family life in the working class, and science in the service of children.

The RAC has an annual competition offering small grants for studies using the archives. More information on the Center, its grants program and bibliography can be found on its website.

I encourage members with an interest both in history and its relevance for current research to explore the possibilities available at the Rockefeller Archive Center. For further information on the recent workshop and plans for follow-up activities - including a maj or conference and possible contributions to the SRCD biennial meeting - members can contact Frank Kessel (kesfam@pdq. net) who collaborated with the RAC in organizing the workshop.

\section{LET US KNOW YOUR NEWS!}

SRCD Members:

Please share your prestigious awards and memberships with us!

Feel free to share this information and send your announcement to either Developments editor at, jonathan.santo@gmail.com or alukowsk@uci.edu.

\section{SRCD}

Contact Information

Membership:

Tel: (734) 926-0617

Fax: (734) 926-0601

Email: membership@srcd.org

Biennial Meeting Program:

Tel: (734) 926-0610

Fax: (734) 926-0601

Email: programoffice@srcd.org

Meeting Registration

Tel: (734) 926-0612

Fax: (734) 926-0601

Email: cirelan@srcd.org

Website:

Email: webmaster@srcd.org 


\title{
“When Policymakers Tie the Hands of Social Science Researchers, They Are Tying Their Own Hands As Well"
}

\author{
by Sarah Mancoll, Martha Zaslow, and Sarah Mandell
}

This is a quote from U.S. Senator Elizabeth Warren of Massachusetts, who is a social science researcher by training. (Prior to entering politics, Senator Warren, a Harvard Law School professor, made important contributions to the understanding of bankruptcy and personal finance.) Senator Warren recently gave an address to members of the Consortium of Social Science Associations (COSSA) - a group of professional associations, scientific societies, universities, centers, and institutes that work together on issues of science policy and of which SRCD is a governing member-in which she spoke to the importance of federal support for the social and behavioral sciences.

Senator Warren knows from first-hand experience about how social science research can inform public policy. As an early career scholar, Senator Warren and colleagues received an NSF grant to study consumer bankruptcy, particularly what factors pushed families over the edge financially. As she explained during her COSSA remarks, the project led to the discovery that, contrary to popular wisdom, the main drivers of bankruptcy are major life events like medical problems and family breakups rather than irresponsible spending. The Bankruptcy Data Project, which grew out of this first NSF grant, continues to collect data today and has been used by over a dozen scholars.

"In a lot of areas, we don't have all the answers. And what we need is not just political will-but rigorous social and behavioral sciences research to provide insight into key questions," Senator Warren explained during her address to COSSA members. "How do we best overcome the effects of poverty to ensure that all children get an education? Can we reduce illness by getting more Americans to engage in healthy behaviors? How do we encourage young people to save for retirement?"

We reported in this column last year that federally funded social and behavioral sciences are in jeopardy. Threats to the peer review process and unique constraints placed on certain types of social and behavioral science research, especially research in the area of political science, have been two major concerns. Broader across-theboard spending cuts that affect funding for research in the behavioral sciences is another maj or issue. At the same time, an executive order from the White House has placed serious constraints on the ability of federal research agency scientists to attend scientific meetings, limiting the degree to which staff from federal research agencies can exchange knowledge with the field and inform researchers of federal research opportunities.

Part of the solution to this complex set of problems is to create more transparency and accountability by helping policymakers and the public better understand what goes into grant funding decisions. To this end, NSF Acting Director Cora Marrett recently announced the creation of the NSF Transparency and Accountability Initiative. Under this initiative, each NSF directorate will create several broad portfolios addressing the mission of the foundation. In order to receive funding, grant applications must fit into one or more of these portfolios. At the same time, NSF will also work with grantees to make sure that grant titles and abstracts are accurate and accessible to the public. It will be important for SRCD members to be aware of and to follow this guidance.

Another part of the solution is for the community of social and behavioral scientists-and scientific associations more broadly - to educate policymakers and the public on the importance of our research. Examples of NSF-funded research with important implications for policy and practice (and acknowledging here the wide range of examples that would also come from research supported by other agencies funding developmental science research) include studies that are telling us more about how infant language skills develop, how high quality sleep contributes to healthy development in preschoolers, and why relationships between teens and their parents matter to the development of teens' interests in STEM (science, technology, engineering, and math) subjects. Although we as child development scientists know why this research is important, we also need to communicate this to people outside of our field.

As Senator Warren noted in her COSSA remarks, "My experience is just one out of so many NSF grantees who have used their funding to change how we think about the economy, human behavior, our communities and our political structure." By helping to inform policymakers and the public about our research and its implications, we will serve both our community of scientists and the broader society. 


\section{Practicing Change: Course Design for Real-World Application}

by Olivia Lima, Augustana College

As educators in child development, we aspire to improve the lives of children by preparing our students to become better parents, voters, and teachers, supporting healthy development in all the roles where they interact with children personally and professionally. However, we also recognize that our students tend to compartmentalize information learned in classes, and may actually neither apply this information in relevant situations, nor even recognize the opportunity to do so. Therefore, if we hope to create long-term behavioral change in our students leading them to parent differently, vote differently, etc. - our best bet is to build into our courses multiple opportunities for students to practice the specific behaviors we want to encourage. This alternative course design builds on pedagogies such as service learning and innovative assessment (as discussed in recent Teaching Corners: Blackwell, 2013; Blankson \& Rochester, 2013). Not only does it encourage active learning, it aims specifically to engage students in precisely the activities we hope they will pursue long-term. The following course activities and assessments are all examples I have used in my upper-level Child Development class to practice behavioral change.

Group research/decision-making projects: Students can work in teams to investigate controversial and timely topics such as adolescent eating disorders and depression, or corporal punishment vs. other forms of discipline. In one such activity, I ask students to imagine that in 5 years they hear about a wonder product purported to enhance infants' cognitive development. As a group, they brainstorm where they could gather information about such a product: e.g., scholarly research, professional societies' websites, and child advocacy groups, as well as popular press coverage and consumer reviews. Then, I assign infant videos (Baby Einstein) as a sample product. In small groups, students research all the sources they previously identified, compile their findings, and discuss how the different information fits together. Finally, each student writes up what personal decision they have reached about using the product, supporting their decision by citing all the different sources examined.

Case studies: Narrative enhances attention and memory; students relish the opportunity to hear, read, or watch personal accounts. Case studies can be supplemented with a wide variety of reading materials (including assessments and research), and are an ideal venue for students to practice making informed decisions that apply developmental science to one individual's unique experience and context. Many prepared cases are available (e.g., Wilmhurst, 2011). In a case activity, I might ask students to complete pre-writing (getting any preconceptions about a disorder out in the open), then read the case. Next, in a small group, students use the jigsaw approach to each research different areas of the scholarly literature (etiology, assessment, treatment, etc.), then gather to discuss their findings. Finally, students write specific recommendations that explicitly identify best practices in the scholarly literature based on details of the particular case.

Service learning: Since I also hope students will learn to support healthy development by changing their direct interactions with children, service learning provides a perfect vehicle for practice. I require every student to select a site where they work all semester (e.g., volunteering or working for pay at a daycare or afterschool program). Crucially, students do not merely log hours; instead, they have to plan and carry out specific activities and observations based on course material. For example, my students typically enj oy learning and then implementing dialogic reading with preschoolers and toddlers (Zevenbergen $\&$ Whitehurst, 2003). After each week's activity, students write posts that reflect on their experience in the context of highly detailed (and properly cited) discussion of course readings.

Applied essay exam questions: Essay questions allow students to practice responding to real-life scenarios by relying on developmental science. Miniature versions of the case studies and topical research discussed above can be used. In addition, final exam questions can require students to creatively synthesize a wide range of material from the term. (Providing a list of sample questions in advance can lead to powerful study sessions.) For example, students might be asked to respond to the following prompt: Your neighbor says she heard a news story about the recent surge in autism diagnoses. "That's a lot of bunk!" she tells you. "My hairdresser says her boy has autism, but there's nothing really wrong with him. It's just an excuse she uses for his misbehaving. Nowadays people want to turn everything into a "disorder'!" Students will undoubtedly encounter such accusations in their real lives. If a student can respond to this allegation with a well-reasoned argument, drawing on a wide base of empirical evidence, that is one battle won for developmental science. 


\section{TEACHERS' CORNER (CONT)}

(cont. from p. 4)

Crucially, practicing change does not take away from students' learning of traditional course material. Although in-depth activities may require a reduction in total topics covered, in my experience students' memory for the topics selected is greatly enhanced. For example, students who complete the group activity on infant video learn much more about the topic (and are more likely to adopt skeptical views) than students who merely hear a lecture. Similarly, having to actually teach a young child in a service setting often motivates students to seek deeper understanding of theory and research as they encounter the limits of their naïve expectations.

When students build the skills to interact successfully with children, to make wise decisions for the children under their care, and to become lifelong learners - willing and able to investigate future developmental issues - we all stand to benefit.

Sample materials available at: practicingchange.pbworks.com. Correspondence concerning this article should be addressed to: Olivia Lima, olivia.lima@augie.edu. This work was originally presented at the SRCD Teaching Institute (April 2013).

\section{References}

Wilmhurst, L. (2011). Child and adolescent psychopathology: A casebook. Thousand Oaks, CA: Sage.

Zevenbergen, A. A. \& Whitehurst, G. J. (2003). Dialogic reading: A shared picture book reading intervention for preschoolers. In A. van Kleeck, S. A. Stahl, \& E. B. Bauer (Eds.), On reading books to children: Parents and teachers (pp. 177-200). Mahwah, NJ : Lawrence Erlbaum Associates.

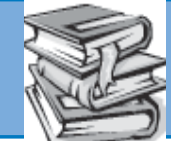

\section{New Books by SRCD Members}

Gable, Sara. (2013). The States of Child Care - Building a Better System. Teachers College Press.

As the U.S. economy continues to falter and families face ongoing wage stagnation and widening income inequalities, there is an urgent need for a better, integrated approach to child care. This accessible, up-to-date account of the chronic issues plaguing child care reform offers viable solutions drawn from a model state child care system in the state of North Carolina. Original data from interdisciplinary research illustrates the complex landscape of U.S. child care as well as the ambiguous relationship society has with the sobering statistic that $64 \%$ of women with children under six are employed and in need of reliable, high-quality care of their young children.

Parke, Ross D. (2013). Future Families: Diverse Forms, Rich Possibilities. Wiley-Blackwell, Malden, MA.

The focus of this book brings together interdisciplinary research on new family forms including single parent families, same-gender parents, new reproductive technology-assisted families, immigrant families, cross cultural insights about family forms, and the implications of these issues for children's social and emotional development. Parke chronicles the changes in the way that parents organize their family roles and responsibilities and challenges the view of the ideal or perfect family form as the two-parent nuclear family rearing their biological offspring. The goal is to generate dialogue about our cultural definition of families and to argue for a broadened view of families beyond some imagined ideal form. A central message is that family process trumps family form. Ways of improving the functioning of a range of family forms not only by informal community-based support but by the development of equitable social policies for all family forms are examined. The book is best thought of as a stimulus to new conversations about our conception of families and an exploration of the implications of changing family forms for children's development. 


\section{SECC REPORT}

\section{How to Survive Graduate School with Children}

by Heather Giles, University of Nebraska at Omaha

Graduate school can be very challenging: learning to juggle research, course work, teaching responsibilities, and a social life is difficult. How about adding children and their developmental needs into the mix? Two keys to successful parenting in graduate school are organization and setting priorities.

Parents have a fundamental responsibility to ensure that their child's social, emotional, and physical needs are met while they are growing up. I learned that putting the children's needs first is very important but also very difficult while attending graduate school. Learning how to manage time for the children, research, course work, and teaching responsibilities is no easy task. Children have homework, after school activities, socialization time (time spent with friends), and other physical needs. In my experience, having a family calendar is a great help in managing all of our responsibilities, schedules, and leisure. The children's activities, special projects, and play dates are recorded along with deadlines for my classes and projects. Keeping track of a spouse's travel schedule and evenings away is also very helpful. The family calendar aided in my ability to plan ahead and allocate the proper amount of time to complete course work and related tasks on time while also being able to allow the children to maintain a social life with friends and activities.

An additional organizational tactic is to take classes, perform research and teaching activities, and complete course work while the children are at school. This allows for the evenings to be free so that one can spend time with the children. Working late in the evening after putting the children to bed or getting up early in the morning to complete work tasks also aids in the ability to successfully accomplish the rigorous graduate school demands. It is not always easy to accomplish everything, but by staying organized and focusing on the end goal, it can be achieved.

Of course, organization is the key for attending graduate school no matter what age, marital status, or child status. Priorities also must be made to ensure that one completes all of the tasks that are important to him or her, and sacrifices must be made on occasion to ensure goals are met. For example, I limited my socialization with friends so that I could complete my work requirements and spend time with my family. Another way to survive graduate school with children is to take classes part-time. Although students who take this path spend more time in graduate school than a traditional full-time student, the end goal is still achieved. Asking for help with housework, laundry, meals, and shopping can also be a great organizational strategy because these are all time-consuming tasks which take time away from the children and studying. Asking for help can be difficult because many motivated graduate students want to be able to do it all, but accepting help will alleviate a lot of stress so the important issues can be attended to without feeling guilty.

As we all know, graduate school is challenging no matter what the age or life station of the student. When children are added into the equation, organization and setting priorities are the keys to success. Setting priorities for the children's well-being and allotting time for course work and other responsibilities allows students to achieve the end goal of successfully completing a graduate program while also attending to and fostering the positive development of the children. 


\section{BUILDING INFRASTRUCTURE WORKSHOP}

\section{Building Infrastructure for International Collaborative Research}

by J ennifer Lansford, Duke University

On September 22-24, 2013, the National Academy of Sciences in Washington, DC convened a workshop entitled "Building Infrastructure for International Collaborative Research in the Social and Behavioral Sciences." The workshop was designed as a follow-up to a workshop held in 2006 at which the overall landscape of international collaborative research was examined, and a number of challenges and issues were identified. The original workshop resulted in a widely-circulated report. The 2013 workshop focused on ways in which universities and collaborative projects have attempted to meet challenges involved in international research.

The workshop was co-chaired by SRCD members J udith Torney-Purta and Oscar Barbarin. Other participating SRCD members included Lonnie Sherrod in his role as Executive Director of SRCD, Martha Zaslow in her role as Director of SRCD's Office for Policy and Communications, and Melissa Menzer who is now with the National Endowment for the Arts. The workshop was organized around four panel presentations and discussions:

- Elements of the organizational infrastructure in the behavioral and social sciences that facilitate international research collaborations (including a presentation by SRCD member Merry Bullock);

- Lead-in and planning in international research collaboration (including a presentation by SRCD member Charles Super);

- Issues in the conduct of internationally collaborative research (including a presentation by SRCD member J ennifer Lansford); and

- Disseminating the products of internationally collaborative research.

Some issues that frequently impede international research include tenure and training policies that militate against the involvement of graduate students and junior faculty, funding that is insufficient for appropriate dissemination, Institutional Review Board (IRB) policies, identifying potential collaborators, and challenges in new web-based environments. Discussions focused on comparing solutions that have worked for different types of institutions, professional associations, and projects. Panels and discussions presented a number of innovative ideas and identified resources that should prove to be helpful to SRCD members interested in participating in international collaborative research. These ideas will be described in a report of the workshop that will be published in 2014 by the National Academy of Sciences and available on their website

The workshop was hosted by the U.S. National Committee for the International Union of Psychological Sciences and supported by the National Science Foundation and the Spencer Foundation. It sought advice from key actors: scholars experienced in conducting international research, academic officials (including deans and directors of international offices), leaders in professional associations, specialists in IRBs, and specialists from agencies and consortia.

For further information, please contact J ennifer Lansford at lansford@duke.edu.

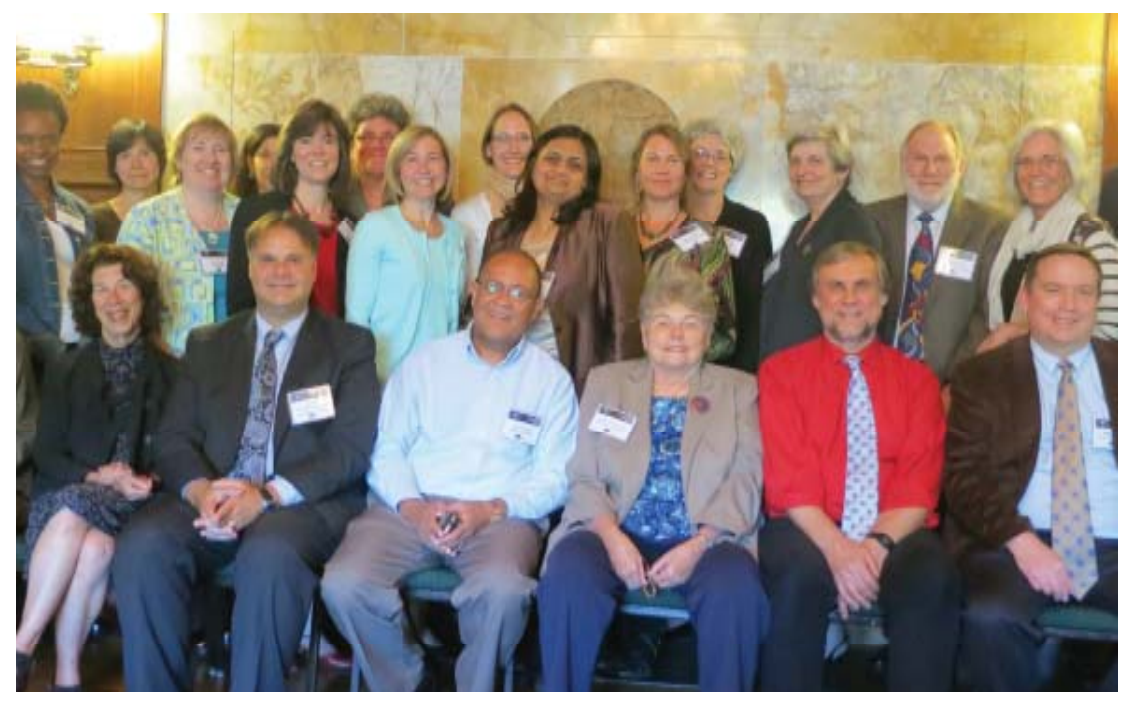




\section{Twenty Most Fascinating Studies in Child Psychology}

\section{Twenty Most Fascinating Studies in Child Psychology}

by Wallace E. Dixon, J r., East Tennessee State University

A little more than a decade ago, I polled the SRCD membership to identify the top studies published in child psychology since 1950. The results of that poll were published in Developments in the early 2000s over a series of articles.

Now, more than 10 years later, I have re-conducted the poll to update the list of the top studies published in child psychology, this time focusing on studies published since 1960. However, in addition to polling the SRCD membership, I have also polled the memberships of two additional societies, namely the International Society on Infant Studies and the Cognitive Development Society. Despite the different emphases of the three societies, there was surprising agreement among the respondents, especially with regard to the highest-ranking studies.

What follows is the first in a series of installments in which I report the outcomes of my "top studies study." In future installments, I will report on the top 20 Most Controversial, Most Important, and Most Revolutionary studies. However, in this installment I report on the 20 Most Fascinating Studies. (For more details on my methodology, you can write to me at dixonw@etsu.edu.)

Now, on to the 20 Most Fascinating Studies published in the field of child psychology since 1960, in reverse order:

20) Baillargeon, R., Spelke, E. S., \& Wasserman, S. (1985). Object permanence in five-month-old infants. Cognition, 20, 191-208.

19) Bowlby, J. (1969). Attachment and loss, Vol. 1: Attachment. New York: Basic Books.

18) Vygotsky, L. S. (1978). Mind in society: The development of higher psychological processes. Cambridge, MA: Harvard University Press.

17) Hart, B., \& Risley, T. R. (1995). Meaningful differences in the everyday experience of young American children. Baltimore, MD: Paul H. Brookes Publishing.

16) Onishi, K. H., \& Baillargeon, R. (2005). Do 15-month-old infants understand false belief? Science, 8, 255-258.

15) Wynn, K. (1992). Addition and subtraction by human infants. Nature, 358, 749-750.

14) Thomas, A., \& Chess, S. (1977). Temperament and development. Oxford, England: Brunner/ Mazel.

13) Sroufe, L. A., Egeland, B., Carlson, E. A., \& Collins, W. A. (2005). The development of the person. New York: Guilford Press.

12) Eimas, P. D., Siqueland, E. R., Jusczyk, P., \& Vigorito, J. (1971). Speech perception in infants. Science, 171, 303-306.

11) Saffran, J. R., Aslin, R. N., \& Newport, E. L. (1996). Statistical learning by 8-month-old infants. Science, 274, 1926-1928.

10) Bronfenbrenner, U. (1977). Toward an experimental ecology of human development. American Psychologist, 32, 513-531.

9) Dodge, K. A. (1980). Social cognition and children's aggressive behavior. Child Development, 51, 162-170.

8) Baron-Cohen, S., Leslie, A. M. \& \& Frith, U. (1985). Does the autistic child have a "theory of mind"? Cognition, 21, 37-46.

7) Petitto, L. A., \& Marentette, P. F. (1991). Babbling in the manual mode: Evidence for the ontogeny of language. Science, 251, 1493-1496.

6) Gottlieb, G. (1991). Experiential canalization of behavioral development: Theory. Developmental Psychology, 27, 4-13.

5) Mischel, W., Shoda, Y., \& Rodriguez, M. I. (1989). Delay of gratification in children. Science, 244, 933-938. 


\section{TWENTY MOst Fascinating. .. (CONT)}

(cont. from p. 8)

4) DeCasper, A. J ., \& Fifer, W. P. (1980). Of human bonding: Newborns prefer their mothers' voices. Science, 208, 1174-1176.

3) Meltzoff, A. N., \& Moore, M. K. (1977). Imitation of facial and manual gestures by human neonates. Science, 198, 75-79.

2) Ainsworth, M. S. (1979). Infant-mother attachment. American Psychologist, 34, 932-937.

\section{And the \#1 Most Fascinating Study in child psychology published since 1960 is...}

1) DeLoache, J. S., Miller, K. F., \& Rosengren, K. S. (1997). The credible shrinking room: Very young children's performance with symbolic and nonsymbolic relations. Psychological Science, 8, 308-313.

\section{FELLOWSHIP OPPORTUNITY}

\section{Post-Doctoral Research Fellowship Developmental Psychology at the University of Michigan}

Applications are now being accepted for a 2-year NICHD post-doctoral research fellowship in Developmental Psychology at the University of Michigan. The Developmental Area will award up to 2 post-doctoral fellowships starting in Fall 2014. The Developmental Area faculty have a broad range of research interests across the life-span from infancy to late adulthood. There are many rich opportunities to pursue research in a number of developmental areas, such as infant-parent attachment, sibling relationships, literacy and school readiness, adolescent academic achievement, racial socialization and identity development, pubertal development, parent-adolescent relations, psychosocial health and future orientation, cognitive aging, neurological basis of adolescent anxiety disorders, media effects, language acquisition, children's conceptual development and social-cognition, social relations across the life-span, and much more. Interested applicants should check the developmental area's website to see the list of core faculty and their interests.

http:// www. Isa. umich. edu/ psych/ programareas/ developmentalpsychology/ developmentalpsychologyfaculty

Fellows are expected to be actively engaged in research during their appointment and will receive additional training in the responsible conduct of research, grant-writing, manuscript preparation, and professional development.

\section{Qualifications:}

The successful candidate will have a Ph.D. in psychology, human development, neuroscience, or related fields, and have a record of research accomplishment in child or life-span development. The individual must be a US citizen or a non-citizen national of the US or have been lawfully admitted for permanent residence in the US. Salary is in line with NIH pay scale. Offer includes full UM health benefits and travel to one conference per year.

Submit CV, cover letter with statement of research interests, 3 letters of recommendation, and evidence of scholarly publications no later than J anuary 31, 2014 to: psychflooradmin@umich.edu.

The University of Michigan, as an equal opportunity/ affirmative action employer, complies with all applicable federal and state laws regarding nondiscrimination and affirmative action. The University of Michigan is committed to a policy of equal opportunity for all persons and does not discriminate on the basis of race, color, national origin, age, marital status, sex, sexual orientation, gender identity, gender expression, disability, religion, height, weight, or veteran status in employment, educational programs and activities, and admissions. 


\title{
Victoria S. LeVin Grant Winner
}

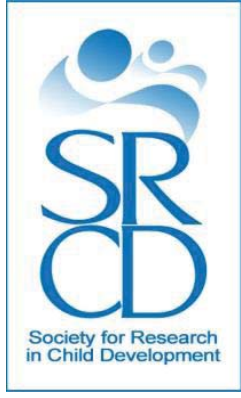

\section{The Society for Research in Child Development}

is pleased to announce the $\mathbf{2 0 1 3}$ Recipient of the

\author{
Victoria S. Levin Grant \\ For Early Career Success in Young Children's Mental Health Research
}

Maureen Zalewski, Ph.D.
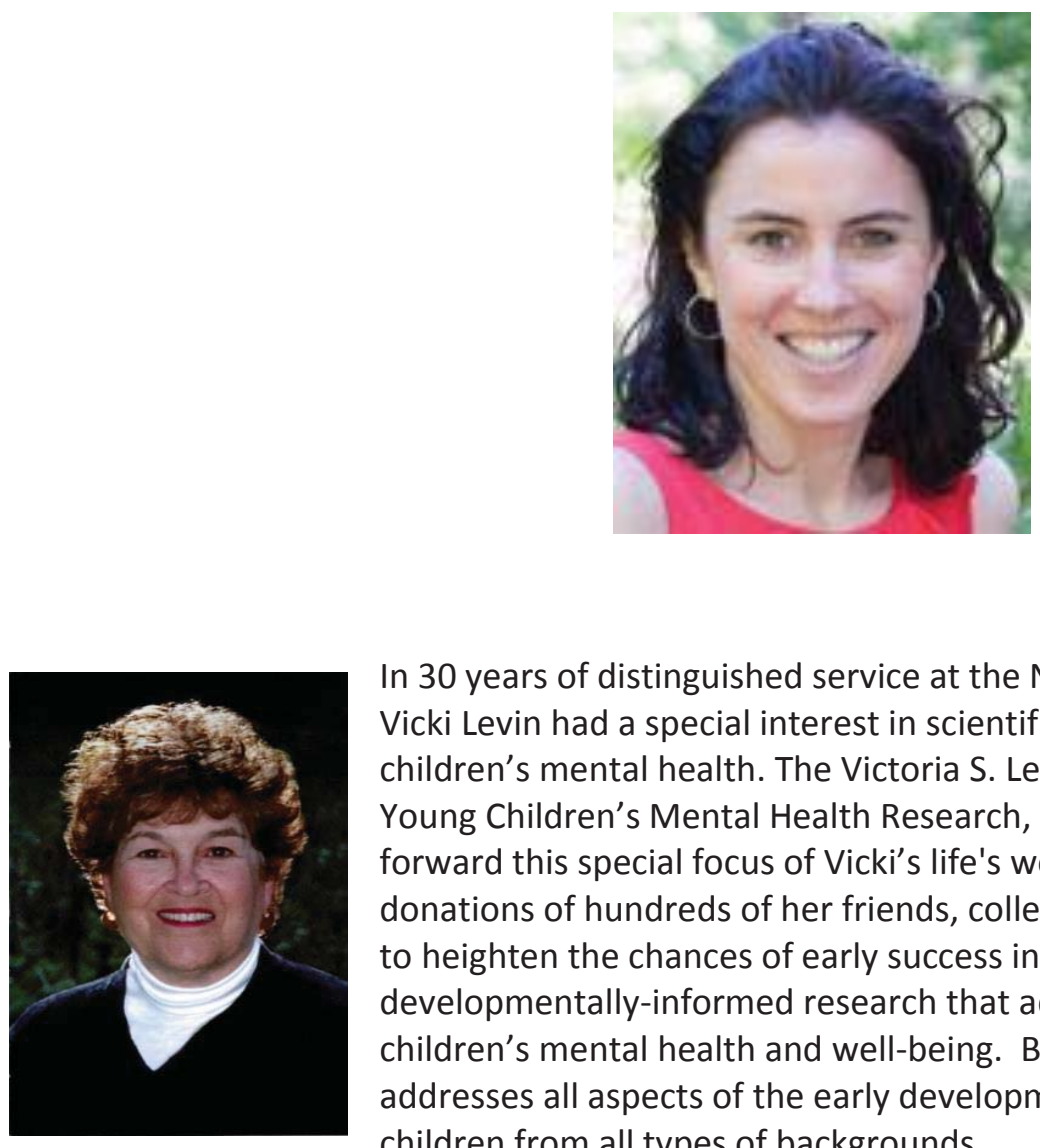

In 30 years of distinguished service at the National Institutes of Health (NIH), Vicki Levin had a special interest in scientific research that addressed young children's mental health. The Victoria S. Levin Grant for Early Career Success in Young Children's Mental Health Research, established to honor and carry forward this special focus of Vicki's life's work, was made possible by the donations of hundreds of her friends, colleagues and family members. Its aim is to heighten the chances of early success in achieving federal funding for developmentally-informed research that addresses the early foundations of children's mental health and well-being. Broadly defined, such research addresses all aspects of the early development of competence and risk for children from all types of backgrounds.

We are very pleased to announce that Dr. Maureen Zalewski is the recipient of the 2013 Victoria S. Levin Grant. Her selected mentor is Dr. Phil Fisher. Dr. Zalewski is an Assistant Professor of Psychology at the University of Oregon. Dr. Zalewski received her BS in Psychology from The Pennsylvania State University, her PhD in Child Clinical Psychology from the University of Washington, and completed a post-doctoral fellowship at the University of Pittsburgh Medical Center. Dr. Zalewski investigates the development of emotion and stress reactivity and regulation in the context of maternal borderline personality disorder. Her work focuses on how emotionally dysregulated parenting and mothers' own trauma experiences influence the physiological and behavioral indicators of children's developing emotion and stress regulation capacities.

Please visit www.srcd.org for more details about the grant and applicant eligibility. Applications for the 2014 Grant will be available on the SRCD website on July 1, 2014. The deadline for applications is September 1, 2014; the grant will be announced in November, 2014. 


\section{Members in the Media}

The SRCD Office for Policy and Communications is interested in highlighting SRCD members and publications featured in the news media. The following are the most recent submissions:

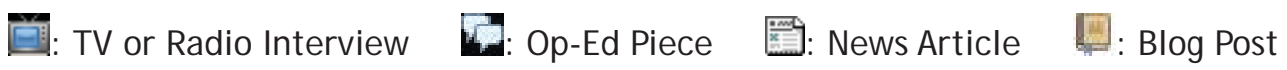

J ay Belsky, Bruce Ellis, Glenn Roisman, \& Marinus Van IJ zendoorn. New Science Stirs Debate. How Behavior is Changed; Who's an Orchid, Who's a Dandelion.

W. Steven Barnett, David Dickinson, Anne Fernald, \& Adriana Weisleder. 兹 The New York Times. Language-Gap Study Bolsters a Push for Pre-K.

* Natasha J. Cabrera and the SRCD Ethnic and Racial Issues Committee. sean. The Roanoke Times. Wisconsin State J ournal. Lubbock Avalanche-J ournal. SRCD Social Policy Report: Positive Development of Minority Children.

Elizabeth Gershoff. 鹚 Chicago Tribune. Spanking Tied to Later Aggression among Kids.

* Sandra Graham, Anke Munniksma, \& J aana J uvonen. 1 The Atlantic. Friendships in Urban Middle Schools Make Youths Feel Less Vulnerable, Safer.

* Sarah Roseberry, Kathryn Hirsh-Pasek, \& Roberta M. Golinkoff. N. Press release: Responsive Interactions Key to Toddlers' Ability to Learn Language.

* Brian N.Verdine, Roberta M. Golinkoff, Kathryn Hirsh-Pasek, Nora S. Newcombe, Andrew T. Filipowitz, \& Alicia

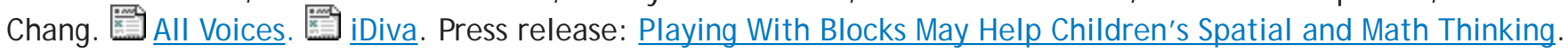

* Hirokazu Yoskikawa, Christina Weiland, J eanne Brooks-Gunn, Margaret R. Burchinal, Linda M. Espinosa, William T. Gormley, J ens Ludwig, Katherine A. Magnuson, Deborah Phillips, and Martha J. Zaslow. The New York Times.

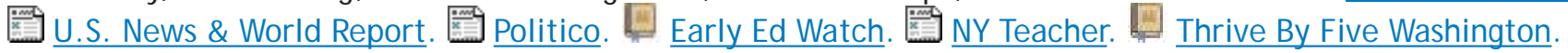
Reporting on Health. Press release: New Research Brief: Investing in Our Future: The Evidence Base on Preschool Education. The full research brief can be found here on the SRCD website.

Charles Zeanah J r. 疅The Root. A 5-Year-Old's Suspected Suicide: When Brandajah Smith Shot Herself, Was It an Accident — or Did She Deliberately Pull the Trigger?

* Indicates media coverage related to an SRCD publication.

We strongly encourage and welcome all members to report recent noteworthy mentions of their research in the media. Information may be emailed to communications@srcd.org.

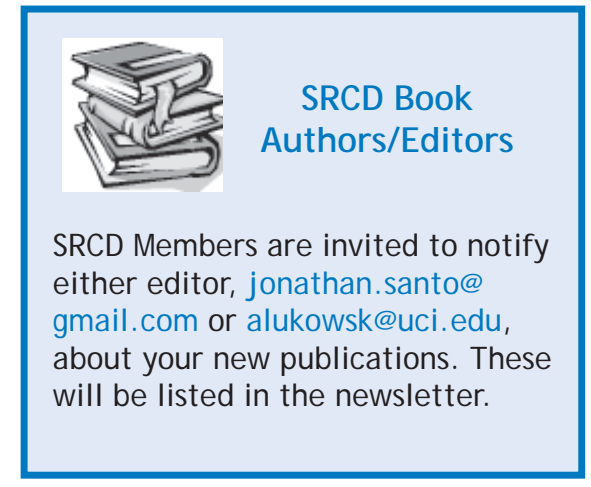




\section{Important Notice}

- J ournals are not forwardable. If you do not notify the SRCD Membership Office of a change of address, you will stop receiving your journals.

- Do not send your change of address to Blackwell Publishers.

- Contact the SRCD Membership Office (Tel: (734) 926-0617; Fax: (734) 926-0601;

E-mail: tandrade@srcd.org if you have concerns or questions regarding your publications or your membership.

- Membership applications are available on the SRCD website.

\section{Change of Address Notification}

Name:

Mailing Address:

Phone:

Fax:

E-mail:

Effective date:

Send to: SRCD Membership, 2950 S. State Street - Suite 401, Ann Arbor, MI 48104; or fax to: (734) 926-0601

\section{Developments' \\ Submission Guidelines}

Text: Provide your material in unformatted text blocks only, preferably using "Trebuchet" 10-pt font in Word or WordPerfect. Word limit for a one page article is 775 words. A photo of the author or topic or both to accompany the article would be greatly appreciated.

Photographs: 300 DPI, "tif" files only. If you do not have a scanner to produce the photo quality we need, Ioan us your photo; we will scan it for our use, and then return it to you. Please send materials to J onathan Bruce Santo, jonathan. santo@gmail.com or Angela Lukowski, alukowsk@uci.edu.

Ads: Contact Amy Glaspie, aglaspie@srcd.org; 734-926-0614 for information and an order form. General ad specs:

- 1/ 8-page display ad is 2" $\times 3.5^{\prime \prime}$ and contains up to 75 words plus a 2-line header

- 1 / 4-page display ad is $3.5^{\prime \prime} \times 4.5^{\prime \prime}$ and contains up to 175 words plus a 2-line header

- $1 / 2$-page display ad is $4.5^{\prime \prime} \times 7.25^{\prime \prime}$ and contains up to 325 words plus a 2-line header

- Full-page display ad is $7.25^{\prime \prime} \times 8.75^{\prime \prime}$ and contains up to 650 words plus a 2-line header

\section{SRCD Developments}

Editors

J onathan Bruce Santo

jonathan.santo@gmail.com

Angela Lukowski

alukowsk@uci.edu

Managing Editor

Amy Glaspie

aglaspie@srcd.org

Teachers' Corner Moderator Katharine Blackwell

katharine.blackwell@salem.edu

SECC Column Moderator

Michelle Wright

mwrigh20@depaul.edu

President

Governing Council

Lynn Liben

President-Elect Ron Dahl

Secretary

Members

Nancy Hill

Robert Crosnoe

Kenneth Dodge

Mary Gauvin

Richard Lerner

Kofi Marfo

Seth Pollak

Kenneth Rubin

Deborah Vandell

Thomas Weisner

SECC Rep

Ex Officio

Dawn England

Lonnie Sherrod

Susan Lennon

Martha Zaslow

The Newsletter is published four times a year: Circulation is approximately 6,000 . The newslettter is distributed to all members of the SRCD including researchers, practitioners in the field of child development, social and behavioral sciences, social workers, administrators, physicians, nurses, educators, and students.

The newsletter publishes announcements, articles, and ads that may be of interest to members of the Society, as space permits. 